\section{FOUNDATIONS ADVANCES}

ISSN 2053-2733

Received 12 March 2021

Accepted 12 March 2021

Keywords: line profile analysis; LPA; whole powder pattern modelling; WPPM; crystalline domain size; corrigenda

\section{Diffraction line profiles from polydisperse crystalline systems. Corrigenda}

\section{Paolo Scardi*}

Department of Civil, Environmental and Mechanical Engineering, University of Trento, 38123 via Mesiano 77, Trento, Italy. *Correspondence e-mail: Paolo.Scardi@unitn.it

Equation (16) and some entries in Table 1 in the article by Scardi \& Leoni [(2001), Acta Cryst. A57, 604-613] are corrected.

The variable $\sigma$ in equation (16) of Scardi \& Leoni (2001) is missing a superscript to indicate that this term should be squared. The correct expression is

$$
M_{l, n}=\exp \left[n \mu+\left(n^{2} / 2\right) \sigma^{2}\right] .
$$

As mentioned previously in Leonardi et al. (2012), there are also some errors in the common volume function (CVF) of the octahedron in Table 1 of Scardi \& Leoni (2001). The same errors are found in Stokes \& Wilson (1942). The coefficients for the case $A \leq B+C$ should read

$$
\begin{aligned}
H_{0} & =1, \\
H_{1} & =-3(A+B+C) / 8^{1 / 2}, \\
H_{2} & =-3\left[A^{2}+(B-C)^{2}-2 A(B+C)\right] / 4, \\
H_{3} & =\left(A^{3}+B^{3}+C^{3}-3 A B C\right) / 2^{1 / 2}, \\
K^{c}(h k l) & =(A+B+C) / 2^{1 / 2} .
\end{aligned}
$$

\section{References}

Leonardi, A., Leoni, M., Siboni, S. \& Scardi, P. (2012). J. Appl. Cryst. 45, 1162-1172.

Scardi, P. \& Leoni, M. (2001). Acta Cryst. A57, 604-613.

Stokes, A. R. \& Wilson, A. J. C. (1942). Proc. Cambridge Philos. Soc. 38, 313-322.

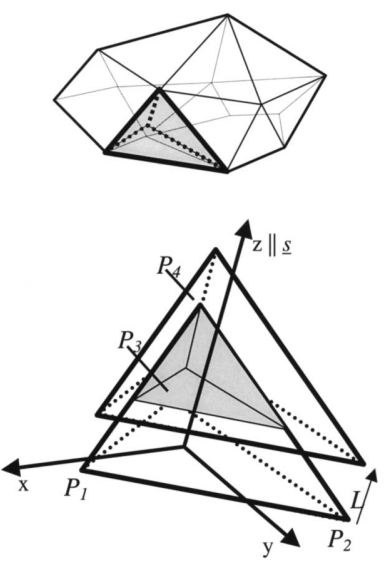

